\title{
Experimental investigation of improving received radiation by an hourly sun tracking on a weir-type cascade solar still
}

\author{
Mahdi Norozi \\ Young Researchers and Elite Club, Ilkhchi Branch, Islamic Azad University, Ilkhchi 5358114418, \\ Iran
}

Email: hadi.irani@yahoo.com

\begin{abstract}
This study considers improving received solar radiation by an hourly sun tracking on a weir-type cascade solar still (WTCSS). The system was adjusted for 6 hours in 6 steps. It included a dual-axis tracking system, with tracking axis fixed by adjustable tilt angles as the monthly optimum tilt angle. And the other one rotating in six hourly position tracking. The control unit was adjusted by Programmable Logic Controller (PLC) and Lab-TAB based on meteorological and geographical data collected for Ilkhchi city in the Northwest of Iran. Obtained results were compared those of the non-sun tracking system. The analytical results show that the daily maximum solar radiation was about $31.5 \mathrm{MJ} / \mathrm{m}^{2}$ in July. The experimental analyses show that received solar intensity on the tilted surface in sun tracking system was about 5 to $12 \%$ more than fixed azimuth angle and 10 to $30 \%$ higher than that of a horizontal surface. The daily maximum solar radiation $\left(\mathrm{H}_{\mathrm{t}}\right)$ obtained in the summer months was between $0^{\circ}$ and $25^{\circ}$. The highest values of the daily beam factor $\left(\mathrm{R}_{\mathrm{b}}\right)$ belong to months December and January. The highest values of calculated hourly productivity for solar still belonged to July and Jun, with 1.1 and $1 \mathrm{~kg} / \mathrm{m}^{2} . \mathrm{h}$, respectively. Energy efficiencies of tracking system have increased significantly than the fixed system.
\end{abstract}

Keywords: Hourly Sun Tracking, Weir-type Cascade Solar Still, Azimuth Angels, Energy Efficiency, Solar Radiation.

\section{INTRODUCTION}

Fresh water shortage has been constantly a serious problem in the world. Although the world's freshwater resources consist of $3 \%$ of the total water resources, it is not distributed equally in all the geographical areas. In the Middle East, the average annual rainfall is less than the world's average. Almost all the countries in the region are suffering from drought and water shortages. Unfortunately, about $40 \%$ of the world population does not access to clean drinking water [1]. Desalination's pollution and rising ocean temperatures, were considered in world climate conference 2015 Paris. Climate change and fossil fuel resources dwindle all water resources, and cause environmental problems. The poor quality of drinking water has children disease in the world in about 2.5 million people [2]. However, the Middle East has good solar radiation resource that can help as clean energy [3]. A new section has been recently being considered, need to be freshwater ecological nature and the environment. Ecological restoration and endangered species need to new water sources. Otherwise, it may also put pressure on other water resources [4]. In many places, the quality of consumed brackish water resources used has harmful effects to health. It is estimated that $28 \%$ of residents of India are suffering this problem. This problem also exists in southern and central regions of Iran. In island countries such as Indonesia, the fresh water production is very expensive [5, 6]. Viola et al. [7], presented the use of renewable energy for desalination plants in Sicily. Although desalination can solve water shortage problem; such systems often have high energy consumption and contaminate the environment. It is estimated that producing of $1000 \mathrm{~m}^{3}$ of fresh water from the sea resources, requires 10,000 tons of oil [8]. To increase the average daily amount of distillate in a solar still, Tanaka [9] presented a theoretical analysis of a basin type solar still with internal and external reflectors.

Solar still is the best alternative for the industrial desalination systems as it has the lowest $\mathrm{CO}_{2}$ emissions and uses free solar energy. Since solar energy is the main factor for evaporation, solar desalination is generally called solar still or distillation. This type of solar still for the first time as the large scale was designed and made by a Swedish engineer Carlos Wilson (1872) to supply water for workers in a mine in Las Salinas, (Chile) and was used successfully for about 30 years. Dunkle (1961) [10] introduced empirical relationships to estimate the energy needed for evaporation process. Received solar energy is absorbed by the black plates and transfer heat to the brackish water. By increasing internal energy, water molecules evaporation process is initiates. Solid salt remains 
at the bottom of basin plates. Evaporated water conducts by the inner surface of the glass acted as a condenser, finally, condensed water is collected. The solar still system is based on brackish water evaporation by solar radiation.

Generally, the top cover is made of glass and absorber basin plate from aluminum painted in by black color. Life Cycle Assessment (LCA) was used to increase the performance of a solar Dish-Stirling [11]. The effect of water $\mathrm{Cu}$ nanofluid was simulated under forced convection heat transfer condition through a flat plate solar collector (FPSC) and enhanced received solar radiation [12]. Tiwari et al. [13] conducted a parametrical study on solar distillation systems and showed that the optimum depth and thickness of insulation for an active solar still was $0.11 \mathrm{~m}$ water depth and $0.03 \mathrm{~m}$ for insulation. El-Sebaii et al. [14] investigated a Single Basin Solar Slope (SBSS) and found that the daily efficiency of the SBSS increased when the water input was preheated with a shallow solar pond. Velmurugan et al. [15-16] and, Tabrizi et al. [17-18], examined the stepped solar still and showed that the performance of this model is about $20 \%$ better than that of an SBSS. The average daily production of stepped systems is 4-7 $\mathrm{kg} / \mathrm{m}^{2}$. This system, however, has its own problems. Cleaning the deposited salt from its stairs is difficult. Also, due to the imbalance of levels, creating a thin layer of water on the channels is very difficult. To solve these problems, Tabrizi used a flow rate to prevent salt deposition and weir. Nevertheless, the outflow of brine from the device will be very salty and cause harm to the environment. In previous studies [19] for increasing the efficiency and recycling the brine, a solar hybrid model was designed by combining a parabolic collector, and cascade solar still, and SBSS as recycling brine. This system can solve brine problem of cascade solar stills since the system efficiency reached about $41 \%$. Solar radiation received by a solar still depends on the tilt and azimuth angels. Abdallah and Nijmeh [20], investigated the effect of using two axes tracking controlled by PLC on the solar energy collected and reported that the measured collected solar energy on the moving surface was significantly larger than that on a fixed surface. Mohammed et al. [21] presented a parabolic solar cooker with two automatic sun-tracking axes. Their results showed that this system improved the performance of the solar cooker. Peragóna et al. [22], analyzed an alternative method for determining the tracking energy advantage, defined as the additional electrical energy produced by two axes tracking systems respective to the fixed devices. The energy yield of this system was $20 \%$ higher than that of most of the fixed systems. Solomona et al. [23], studied the hourly generation data from the Israel Electric Corporation for the year 2006 by extending PV system simulations are extended to include the cases of 1,2-axis and 2-axis concentrator photovoltaic (CPV) technologies. They reported that sun tracking improves grid matching at high but not low levels of grid flexibility. Chong and Wong [24] derived the general formula for one-axis suntracking system based on coordinate transformation method [24]. The application of the general formula improved an ideal azimuth-elevation or tilt-roll tracking accuracy during its installation. Seme et al. $[25,26]$ evaluated the maximum efficiency of PV sun tracking system obtained based on optimal trajectories of the tilt and azimuth angles. The results showed that the maximum energy yield of the solar radiation was at the highest level when using the dual axis sun tracking. A series of spinning-elevation tracking formulas was considered for dual-axis tracking toroidal heliostat. This method presented details and analyzed the accuracy of applying simplifying approximation [27]. Huang et al. [28] analyzed an azimuth tracking linear Fresnel solar concentrator (ATLFSC) installed on an azimuth tracker. They reported that annual mean total efficiency of ATLFSC reached $61 \%$ that is better than that of fixed linear Fresnel reflector (36-57\%). Farooqui $[29,30]$ investigated dual booster mirror s-tracking and linear tracking system with solar cookers. This system was adjusted for up to six hours, starting $3 \mathrm{~h}$ before solar noon and up to $3 \mathrm{~h}$ after it. Maximum exergy efficiencies for output power in cookers reached 2.5 to $4.5 \%$ between $12: 30$ p.m. to 15:30p.m. of local solar time. Bakos [31] compared a two-axis solar tracker with a fixed surface tilted for the efficiency of the parabolic through the collector (PTC). It was observed that the measured collected solar energy on the tracking system was significantly more (up to $46.46 \%$ ) than that of a fixed surface. Kalogirou [32] designed and constructed a one- axis sun tracking system with a control system adjusted by three lightdependent resistors (LDRS). One of these resistors detects whether the collector is focused, the second resistor determines if there is any cloud cover, and the third one finds whether it is day or night. Reisi et al. [33], classified suntracking methods into three broad categories: offline methods, online methods, and hybrid methods. In offline methods, usually, the physical values are used to adjust the control system. But, in online methods, the instantaneous values are typically applied to generate the control signals. In hybrid methods, two mentioned methods are used either at the same time or separately.

\section{DESIGN OF WEIR WEIR-TYPE CASCADE SOLAR STILL (WTCSS)}

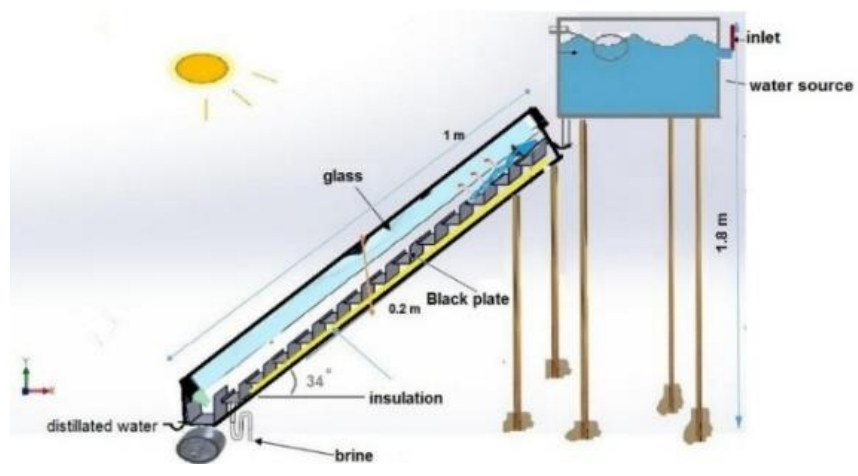

Figure 1. A schematic of weir type cascade solar still

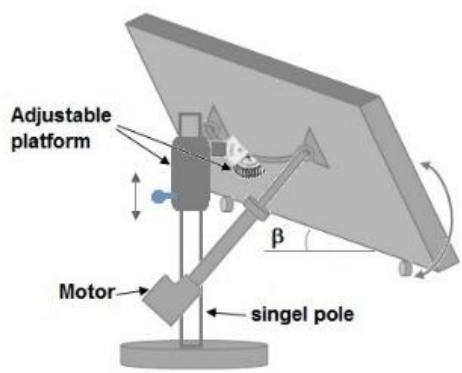

Figure 2. A schematic diagram of the designed sun tracking

In this study, the depth of channels (steps) of cascade solar still was selected based on the designs of Tabrizi et al. [17-18], Omara et al. [34], and Velmurugan et al. [15-16], who 
recommended it less than $5 \mathrm{~mm}$. The slope of channels is one of the most important factors in designing cascade solar stills. If the channels slope is greater than the device slope, water flows in the negative slope and prevents uniform water depth distribution. Thus, water is draining quickly in one part and the depth increases in the other parts. Increasing the water depth causes productivity reduction. If the slope of channels becomes larger than the slope of the device, water flows quickly on channels and reduces productivity rate because the time of heat transfer from black plates to water is not enough. The model shown in Figure 1 is a fixed stepped solar still, which is made up of a weir in stairs, absorber plate, security glass cover as a condenser, and the frame covered by glass wool as the insulation. This design won the first award in the competitions of solar still design in the $23^{\text {rdth }}$ conference Iranian Society Mechanics Engineering, (ISME) (2014).

\section{EXPERIMENTAL SETUP AND PROCEDURE}

In this study, WTCSS (Figure 1) and a sun tracking system was designed and fabricated in Islamic Azad University of Iran, Ilkhchi Branch to, investigate the thermal performance of hourly sun tracking system shown in Figures 3 and 4. This device connects to a vertical axis that is able to rotate in an east- to -west direction and vice versa. A schematic of the system is shown in Figure 2.

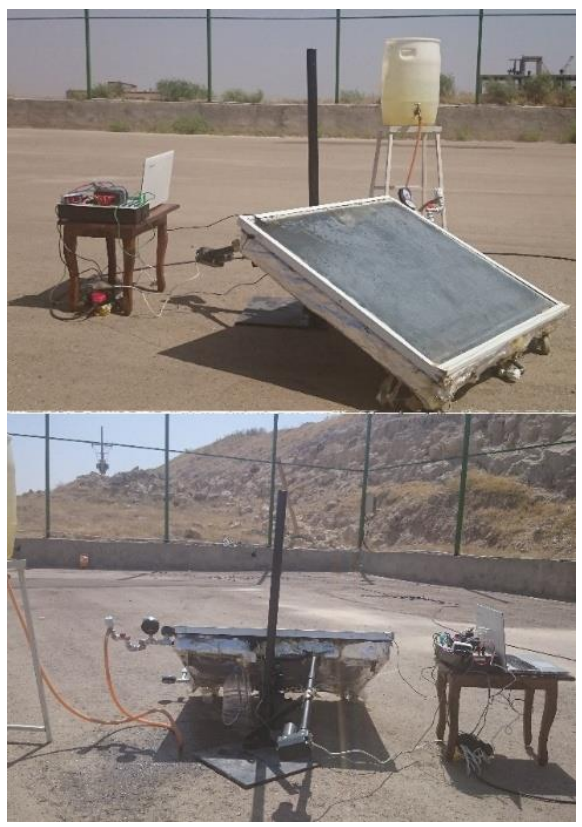

Figures 3-4. Fabricated hourly sun tracking WTCSS

The sun tracking system used in this study included two axes, which adjust the tilt angle and azimuth, respectively. The second axis was rotating by an electro motor, Programmable Logic Controller (PLC) and Lab-TAB (Figure 4). In cascade solar stills, the slope of stairs is usually designed based on the annual optimal slope and can be Rarely, used for monthly an optimal slope. The optimal tilt angle on August, for Ilkhchi Branch, Islamic Azad University (near the city of Tabriz), is about $18^{\circ}$. This angle is controlled manually and fixed at $34^{\circ}$. The average monthly and yearly optimum tilt angles are given in Figure 7. In this paper, solar radiation was measured in hourly azimuth angles with the tracking system and compared with fixed azimuth angle and estimated the performance of
WTCSS. Solar radiation measurements were made using MIC-98206 solar power meter with an accuracy was of $0.1 \mathrm{~W} / \mathrm{m}^{2}$. The water was poured inside the device as the amount capacity of solar still for the accuracy of the experiment. Internal heat performance of cascade solar still will be considered by another paper. According to data from University of Tehran Institute of Geophysics, on August 20 to 21, of 2016 in Islamic Azad University Ilkhchi Branch the time of solar noon occurred at 13: 31 to $13: 28$ (12p.m. central standard time) in test location ( $37^{\circ} 57^{\prime} 13.72^{\prime \prime} \mathrm{N}, 46^{\circ} 5^{\prime} 59.9^{\prime \prime}$ E) [33]. Duration of an experiment for rotation of tracking based on solar times was 6 hours; three hours before solar noon and three hours after it. The time of the test of sun tracking started from 10:32a.m. to 4:32p.m., with the rotation path shown in Figure 5. Hourly angles (h) rotated on earth's surface as $15^{\circ}$ at 1 hour. Electric motors of tracking system were controlled by a computer program and PLC for each hour. So, the rotation domain axis of the system was adjusted to 0 to $90^{\circ}$ and the azimuth angle at the (10:32p.m.) was $\gamma=-45^{\circ}$.

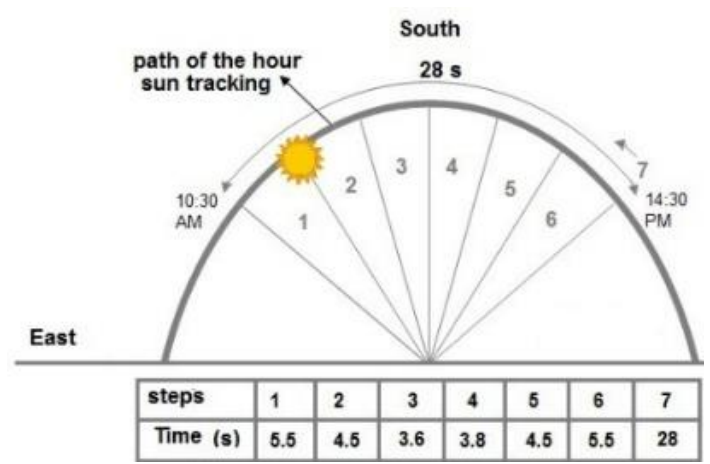

Figure 5. Path of sun tracking and time period of each steps

\section{THEORETICAL ANALYSIS}

\subsection{Solar angels}

The performance of a solar distillation is related directly to the intensity of solar energy. The purpose of this study is to design a model that can use received radiation close to the maximum potential radiation energy at each area of solar still. In this experiment, the effects of solar radiation on sun hourly tracking system of WTCSS are investigated. Although the internal heat transfer and evaporation processes of WTCSS are not studied in this paper. Generally, the performance of WTCSS and energy and exergy efficiencies evaluated by the hourly sun-tracking model. The glass surface of solar still is similar to that of a solar collector, but it passes a large part of the radiant energy. The general formula for on-axis suntracking system based on coordinate transformation method was derived by Chong and Wong [24]. The application of the general formula improved an ideal azimuth-elevation or tiltroll tracking accuracy during its installation its.

Mathematically, sun position $S$ can be obtained as [24]:

$S^{\prime}=\left[\begin{array}{l}S_{V} \\ S_{H} \\ S_{R}\end{array}\right]=\left[\begin{array}{c}\sin \alpha \\ \cos \alpha \sin \beta \\ \cos \alpha \cos \beta\end{array}\right]=[\zeta][\lambda][\phi \zeta][\Phi]\left[\begin{array}{c}\cos \delta \cos \omega \\ -\cos \delta \sin \omega \\ \sin \delta\end{array}\right]$

where, $[\Phi]$ is an earth-center frame to earth - surface frame 
through transformation matrix, $[\phi]$ is earth-center frame to earth - surface frame through transformation matrix, $\lambda$ is declination angle, $\omega$ is hour angle, $\Phi$ is latitude angle, $\beta$ is rotational angle, $\alpha$ is solar altitude angle in the collector-center frame, and $\zeta, \phi$ and $\zeta$ are the first, second and third tilted angle (in tracking system). Klein and Theilacker [35, 36] presented a method (according to KT model) for calculation of the global and daily solar diffuse radiation on an inclined surface:

$R=D+\frac{\bar{H}_{d}}{\bar{H}}\left[\frac{1+\cos \beta}{2}\right]+\rho_{g}\left[\frac{1-\cos \beta}{2}\right]$

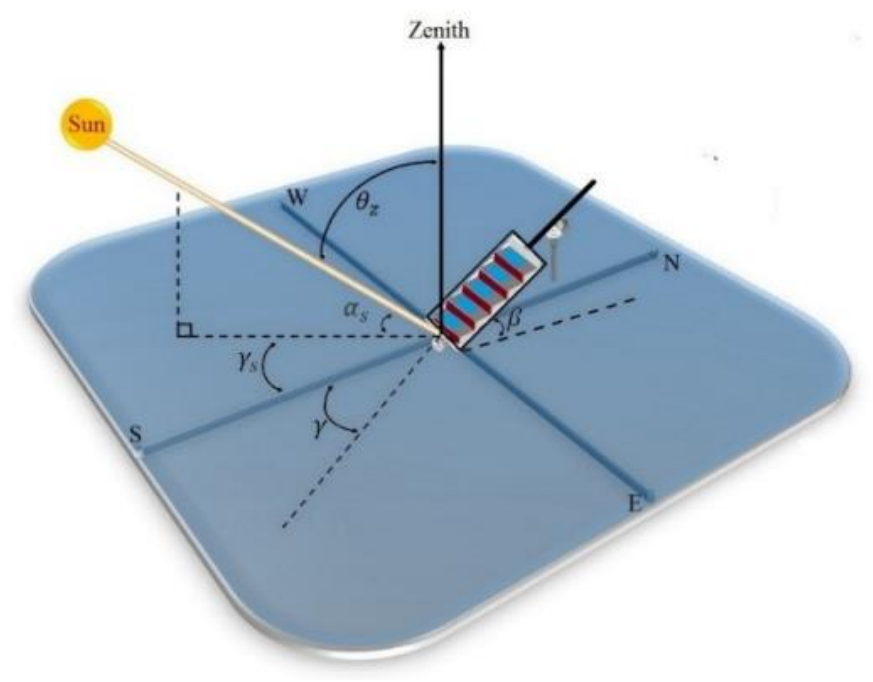

Figure 6. Azimuth angle $\left(\gamma_{s}\right)$, solar altitude angle $\left(\alpha_{s}\right)$, tilt (slope) angle $(\beta)$ and zenith angle $\left(\theta_{\mathrm{z}}\right)$

where $\beta$ denotes the title angle, $\mathrm{D}$ is ratio of beam solar radiation on inclined plate, $\mathrm{R}$ represents the ratio of monthly average daily global solar radiation on inclined plate, $\bar{H}_{T}$, $\left(\bar{H}_{T}=R \times \bar{H}\right)$ is total radiation incident on horizontal surface in day $\left(\mathrm{MJ} / \mathrm{m}^{2}\right)$, and $\bar{H}_{d}$ is diffuse radiation incident on a horizontal surface in a day $\left(\mathrm{MJ} / \mathrm{m}^{2}\right), \rho_{g=0.2}$. For solar radiation incident with one axis, three terms can be written for the tracking system $[37,38]$ :

$I_{T}=I_{c b} R_{b}+I_{c d}\left[\frac{1+\cos \beta}{2}\right]+I_{c} \rho\left[\frac{1-\cos \beta}{2}\right]$

where, $\rho$ is the ground reflectance $(0.7$ for snow 0.2 for snowfree conditions), $\beta$ is slope, $I_{c b}$ is the horizontal beam radiation in clear sky,

$R_{b}=\frac{\cos \theta}{\cos \theta_{z}}$

For each hour, the average hourly radiation incident on the collector is as follow [37]:

$\bar{I}_{T}=\left(\bar{H} r_{t}-\bar{H}_{d} r_{d}\right) R_{b}+\bar{H}_{d}\left[\frac{1+\cos \beta}{2}\right]+\bar{H} \rho_{g} r_{t}\left[\frac{1-\cos \beta}{2}\right]$

where, $\bar{H}_{d}$ is daily diffuse radiation, $r_{d}=\frac{\bar{I}_{d}}{\bar{H}_{d}}, \bar{I}_{d}$ is hourly diffuse radiation, $r_{t}=\frac{I}{H}$, and $\mathrm{I}$ and $\mathrm{H}$ are hourly total radiation and daily total radiation, respectively. Solar altitude $(\alpha)$, the tilt angle $(\beta)$ and rotating mechanism with other solar angles shown in Figure 6. Tilt angle of the device is adjusted based on the optimal annual tilt angle, it is about $34^{\circ}$. Altitude $(\alpha)$ angle can be obtained [22]:

$\sin \alpha=\sin \delta \sin \emptyset+\sin \delta \sin \emptyset \cos h \cos \delta=\sin \delta \sin \emptyset+$ $\cos \delta \cos h \cos \emptyset$

For solar noon the hour angle $\mathrm{h}=0$, so:

$\alpha=\arcsin (\cos (\delta-\emptyset)$

where, $0^{\circ} \leq \alpha \leq 90^{\circ}$ and $\emptyset$ is the angular location north or south of the equator to north direction $\left(-90^{\circ} \leq \emptyset \leq 90^{\circ}\right)$ [35]. In order to evolution of the latitude differences optimum tilt angle can be obtained [40]:

$\beta_{\text {opt }}=\varphi-\delta+10$

The monthly average daily total solar radiation on a tilted surface can be obtained by [14]:

$H_{t}=H_{b} R_{b}+H_{d} R_{b}+H \rho R_{r}$

where $\rho$ is ground reflectivity, Ht is monthly average daily global solar radiation on horizontal surface, and $R_{b}$ and $R_{r}$ are the beam and ground reflected radiation conversion factors, respectively. Global $(\bar{H})$, diffuse $\left(\bar{H}_{d}\right)$ and other solar radiation factors calculated for this study are reported in Table 1 .

Table 1. Solar angles and radiation factors of this system

\begin{tabular}{|l|c|c|c|c|c|c|c|}
\hline Month & $\bar{H}$ & $\bar{H}_{d}$ & $\bar{H}_{0}$ & $\bar{K}_{T}$ & $\bar{G}_{B t}$ & $r_{d}$ & $r_{t}$ \\
\hline Aug & 26.5 & 8.51 & 35.02 & 0.61 & 972 & 0.12 & 0.14 \\
\hline
\end{tabular}

Global $(\bar{H})$, diffuse $\left(\bar{H}_{d}\right)$, extraterrestrial monthly average daily radiation $\left(\bar{H}_{0}\right)\left(\mathrm{MJ} / \mathrm{m}^{2}\right)$, clearness index $\left(\bar{K}_{T}\right)$, beam radiation on a tilt surface $\left(\bar{G}_{B t}\right)\left(\mathrm{W} / \mathrm{m}^{2}\right)$ ratio of hourly diffuse radiation to daily diffuse radiation $\left(r_{d}\right)$ and ratio of hourly total radiation to daily total radiation $\left(r_{t}\right)$ in Ilekhchi.

\subsection{Azimuth angle}

As shown in Figure 6, azimuth angle between the projection on horizontal surface and reference vector (usually driven south or north on the horizontal plane), in solar noon is zero in due south, west positive and east negative $\left(-180^{\circ} \leq \gamma \leq\right.$ $\left.180^{\circ}\right)$, for tracking system $\left(-90^{\circ} \leq \gamma_{s} \leq 90^{\circ}\right)$, which is given by $[35,40]$ :

$\gamma=\arctan \left(\frac{\sin h}{-\cos \emptyset \tan \delta+\sin \emptyset \cos h}\right)$

where $\mathrm{h}$ is hour angle $\mathrm{h}$. For the afternoon when, $\gamma=0$ :

$h=\arccos (\cot \varnothing \cdot \tan \delta)$

The calculated azimuth angels of sun tracking cascade solar still are reported in Table 2. 
Table 2. Declination, hourly, altitude, azimuth angles and hourly daily radiation of the system

\begin{tabular}{|c|c|c|c|c|c|c|}
\hline steps & $\begin{array}{c}\text { Solar } \\
\text { time(CST) }(\mathrm{h})\end{array}$ & $\begin{array}{c}\text { Declination } \\
\text { Angles } \\
(\mathrm{deg})\end{array}$ & $\begin{array}{c}\text { Hourly } \\
\text { Angles } \\
(\mathrm{deg})\end{array}$ & $\begin{array}{c}\text { Altitude } \\
\text { Angles } \\
(\mathrm{deg})\end{array}$ & $\begin{array}{c}\text { Azimuth } \\
\text { Angles } \\
(\mathrm{deg})\end{array}$ & $\begin{array}{c}\text { Hourly } \\
\text { Radiation } \\
\left(\mathrm{MJ} / \mathrm{m}^{2}\right)\end{array}$ \\
\hline 1 & $9: 00$ & 11.07 & -45 & 40.54 & -64.16 & 2.21 \\
2 & $10: 00$ & 11.07 & -30 & 51.72 & -52.18 & 2.9 \\
3 & $11: 00$ & 11.07 & -15 & 61.65 & -35.74 & 3.45 \\
4 & 12 & 11.07 & 0 & 62.05 & 0 & 3.91 \\
5 & $13: 00$ & 11.07 & 15 & 61.65 & +35.74 & 3.45 \\
6 & $14: 00$ & 11.07 & 30 & 51.72 & +52.18 & 2.9 \\
7 & $15: 00$ & 11.07 & 45 & 40.54 & +64.16 & 2.21 \\
\hline
\end{tabular}

\subsection{Sunrise, sunset times}

The azimuth angles displayed with $360^{\circ}$ in a circular path of the sun from East to West. The sunrise hour angle is given as [35]:

$\omega_{s}=\cos ^{-1}(-\tan \varphi \cdot \tan \delta)$

where $\delta$ is declination angle, that can be obtained as:

$\delta=23.45 \sin \left(\frac{\left(n_{\text {day }}+284\right) 360}{365}\right)$

The hour angle can be written as:

$H=15\left(\frac{T_{s}}{2}-\theta\right)$

where, $T_{s}$ is time from sunrise to sunset, $\theta$ is the time after sunrise and $\mathrm{H}=0$ in solar noon and is positive in the morning. When the position of the sun is on the celestial globe at 12 o'clock, the azimuth angle and zenith angle can be obtained by following equations [35]:

$\cos \theta_{z}=\cos \varphi \cos \delta \cos \omega+\sin \varphi \sin \delta$

$\gamma_{s}=\sin \omega\left|\arccos \left(\frac{\cos \theta_{z} \sin \varphi-\sin \delta}{\sin \theta_{z} \cos \varphi}\right)\right|$

where, these angles toward the east $(<0)$ and west $(>0)$, to the south direction. The sunset $\left(\omega_{s s}\right)$ hour angles should be expressed geometry position of inclined cascade solar still, which can be obtained by $[35,36]$ (some references denote hour angle by "h"):

$\left|\omega_{s s}\right|=\min \left[\omega_{s}, \cos ^{-1}\left(A B-C \sqrt{A^{2}-B^{2}+C^{2}} /\left(A^{2}+\right.\right.\right.$

$\left.\left.C^{2}\right)\right]$

$\omega_{s s}=\left\{\begin{array}{c}-\left|\omega_{s s}\right| \text { if }(A>0, B>0) \text { or } A \geq B \\ +\left|\omega_{s s}\right| \text { if otherwise }\end{array}\right.$

where $\mathrm{A}, \mathrm{B}$, and $\mathrm{C}$ are functions of solar geometry and solar collector position. The solar time and azimuth angles calculated (or rotation angles) in Table 1, for a seven-step tracking system and $\beta=34^{\circ}$ in south facing cascaded solar still. Day length can be obtained as [35]:

Day length $=2 / 15 \cos ^{-1}[-\tan L \tan \delta]$

Day length was calculated about $13.07 \mathrm{~h}$, for 19 and 20 August 2016 in the test location. It seems that the amounts of the diffuse radiation are not much different for sun tracking and non- sun tracking model. However, it is predicted that the visibility scope slightly reduced diffuse and reflected radiation on the sun-tracking model. The diffuse radiation $I_{d}\left(\mathrm{~W} / \mathrm{m}^{2}\right)$ according to the ASHRAE is given by [41]:

$I_{d}=C I_{n} F_{s s}$

where, $F_{S s}$ (dimensionless) is the angle factor between the glass surface of WTCSS and sky and, C is the ratio of the diffuse radiation on a horizontal under a cloudless sky to the direct normal irradiation $I_{n}$.

\subsection{Energy balance on WTCSS}

The energy balance for the output brine on each stair can be written as [29-30]:

$q_{a b s, w}+\dot{m}_{i} h_{i}-\left(q_{r, w}+q_{c, w}+q_{e, w}+q_{l, w}\right)-\dot{m}_{o} h_{o}=(\rho V-$

$\left.\dot{m}_{e} d t\right) C_{w} \frac{d T_{w}}{d t}$

The energy balance for the glass cover:

$$
\begin{aligned}
I(t)_{s} \alpha_{g}+h_{t, w-g}( & \left.T_{w}-T_{g}\right) \\
& =h_{t, g-a}\left(T_{g}-T_{a}\right)+h_{r, g-s}\left(T_{g}-T_{s}\right) \\
& +\frac{M_{g} C_{g}}{A_{g}} \frac{d T_{g}}{d t}
\end{aligned}
$$

And for brackish water (saline water):

$I(t)_{s} \tau_{g} \alpha_{w}+h_{w}\left(T_{b}-T_{w}\right)=h_{t, w-g}\left(T_{w}-T_{g}\right)+\frac{M_{w} C_{w}}{A_{w}} \frac{d T_{w}}{d t}$

For the absorber plate, received energy is equal to energy lost to water and ambient:

$I(t)_{s} \tau_{g} \alpha_{b} \tau_{w}=h_{w}\left(T_{b}-T_{w}\right)+U_{b}\left(T_{b}-T_{a}\right)+\frac{M_{b} C_{b}}{A_{b}} \frac{d T_{b}}{d t}$

The hourly yield of solar still is estimated as [42-45]:

$m_{e w}=\frac{h_{e, w-g} A_{W}\left(T_{W}-T_{g}\right)}{h_{f g}} \times 3600$

where $h_{e, w-g}$ and $h_{f g}$ are the evaporation heat transfer coefficients between saline water and glass; latent heat evaporation, respectively.

\subsection{Energy efficiency}

Generally, the energy equations of cascade solar still are 
similar to single basin solar still. In fact, each stair of cascade solar still can be simulated as a single basin solar still. The energy efficiency of a sun tracking- cascaded solar still system could be expressed as for the absorber plate of the basin liner, the energy received is equal energy losses to water and ambient and energy gains can be written as:

$\eta_{d}=\frac{\dot{\sum} m_{e w} \times h_{f g}}{\sum_{t=1}^{24}\left(A_{s} \times I_{s}(t)\right)+\dot{W}_{\text {tracker }}}$

where $\dot{m}_{e w}$ is hourly yield $(\mathrm{kg} / \mathrm{h}), h_{f g}$ is latent heat $\mathrm{J} \mathrm{Kg}^{-1}$ and $A_{S}$ is area of the solar still $\left(\mathrm{m}^{2}\right) . I_{S}(t)$ is the solar intensity, W is work of tracking-motor.

\section{RESULTS AND DISCUSSION}

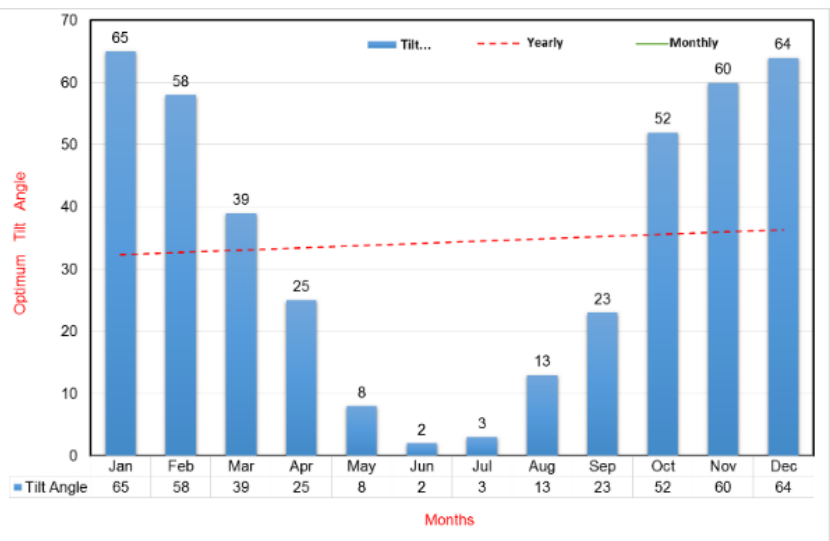

Figure 7. The optimal monthly and annual tilt angles

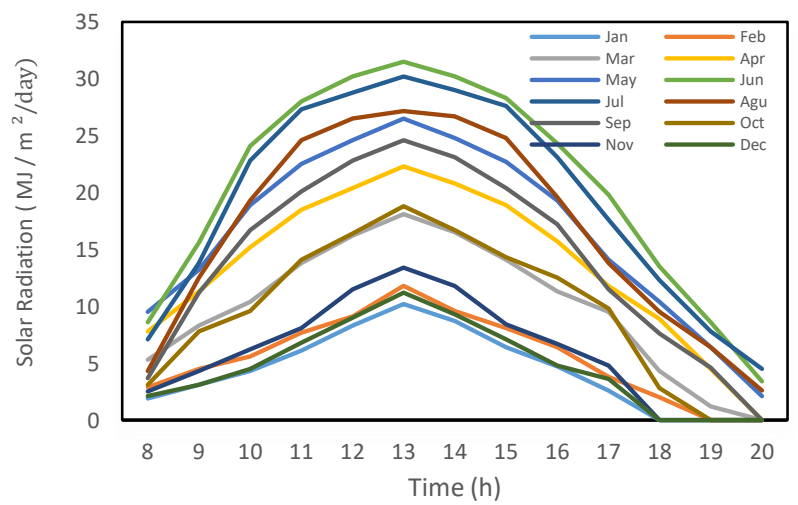

Figure 8. Monthly average of solar radiation on tilted surface with sun tracking

In this research, we investigated the solar performance of hourly sun tracking of a WTCSS. For the proposed model, a sun tracking system was designed, fabricated, and tested on WTCSS (Figure 3 and Figure 4). The monthly average optimum tilt angle of the inclined surface for each month for Tabriz (Ilkhchi is a part of Tabriz), in the northwest of Iran, is shown in Figure 7. As the results show, the maximum and minimum values belong respectively to winter and summer months. Solar altitude is high in June and July, when the sun is shining directly on the surface. Similar results were reported by Jafarkazemi et al. for Dubai [46]. Figure 8 shows total solar radiation on the inclined surface for months, calculated based on a 2-axis solar tracking system assumed for monthly optimum tilt and hourly azimuth angles with sun tracking. As can be seen from these data, the the maximum value obtained is $\sim 31.5 \mathrm{MJ} / \mathrm{m}^{2}$. day during June while the The minimum value of solar radiation was found to be $\sim 11.2 \mathrm{MJ} / \mathrm{m}^{2}$.day during January at solar noon. Similar behavior for solar radiation of non- sun tracking system was presented by Jafarkazemi et al. [36], El-Sebaii et al. [14], and Stanciu et al. [45] and almost similar result were reported by Oladiran [46] for the mean monthly radiation with various azimuth angles.

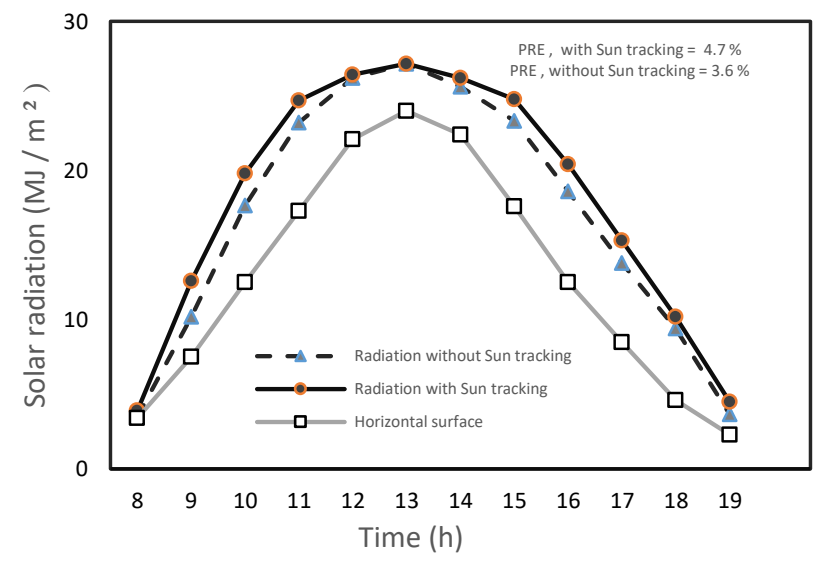

Figure 9. Comparison of experimental solar radiation for sun tracking and non-sun tracking

Figure 9 presents the measured data of the hourly solar radiation compared with a non- sun tracking system and horizontal surface. In both experiments, the optimum tilt angle was adjusted as $34^{\circ}$. As can be seen from Figure 9, the maximum values were obtained at solar noon and the values of non- sun tracking system during 8 to $12 \mathrm{a} . \mathrm{m}$. and 2 to $8 \mathrm{p} . \mathrm{m}$. are less than sun tracking system, but these values are equal during solar noon for fixed system and tracking system. Thus, it can be stated that the average hourly solar radiations of sun tracking mode are about 5 to $12 \%$ more than those of a nonsun tracking system and while the values of the horizontal surface about are 10 to $30 \%$ less than tracking system duringthe day. In the similar sun tracking systems these results are consistent with those presented by Ai et al. [47], Mousazadeh et al. [48], and Sefa et al. [49]. To analyze the errors of the measured data of solar radiation and calculated data, the relative percentage error (RPE) was used:

$P R E=\frac{H_{i, c}-H_{i, m}}{H_{i, m}} \times 100(\%)$

RPE values for solar radiation in the experiment for hourly sun tracking and non- sun tracking were 4.7 and 3.6, respectively. Figure 10 compares ordinary glass with security glass for the light transmittance. The results show that in the solar stills the obtained gain of security glass is about 5 to $15 \%$ more than that of ordinary glass, but the light transmittance of the security glass about 3 to $10 \%$ less than ordinary glass, on glass thickness. The monthly average daily total solar radiation (Ht) for various tilt angles with hourly sun tracking system is plotted in Figure11 and Figure 12. The annual optimum tilt angles for each month (based on the recorded data from Figure. 11), was numerically calculated and presented $H_{t}$ in Figure 11 and Figure 12. 


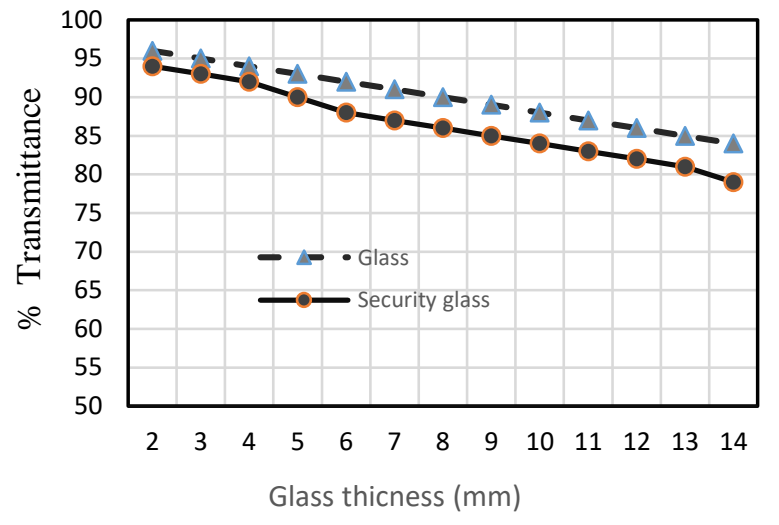

Figure 10. Comparison of solar radiation transmits for security glass and ordinary glass
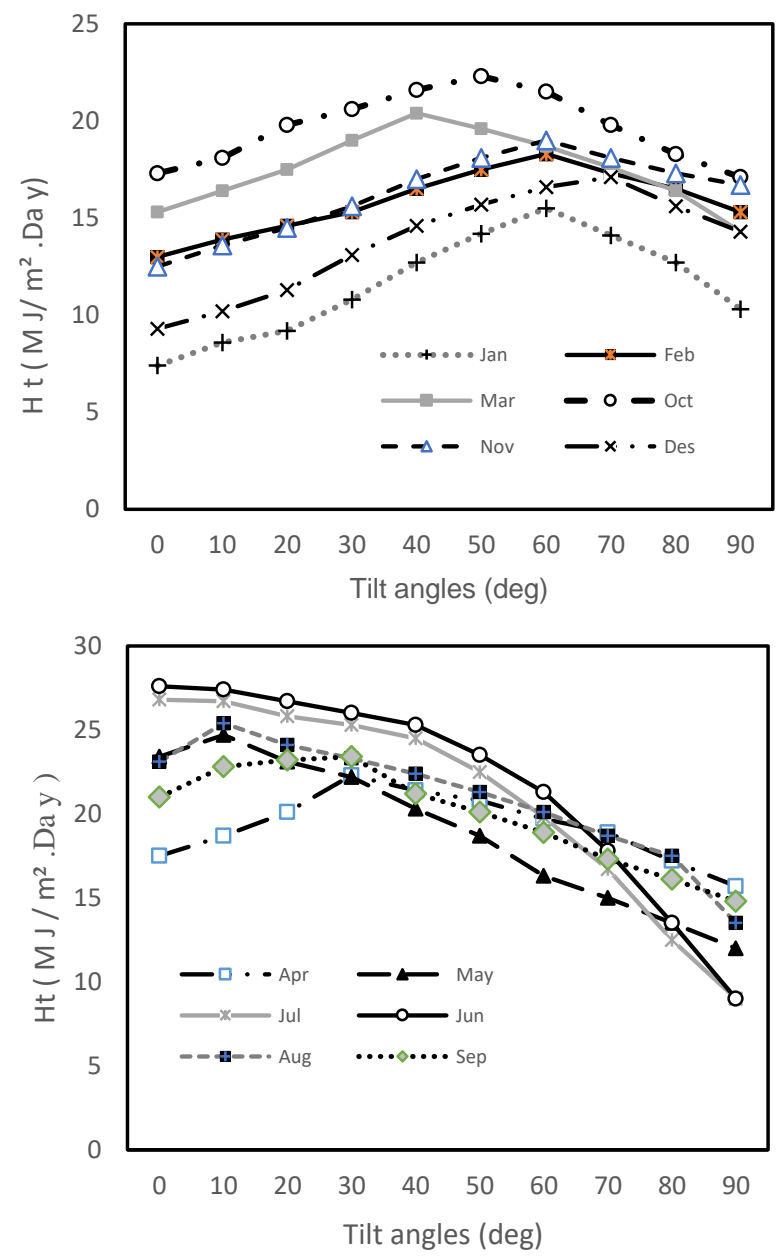

Figures 11 and 12. The monthly average daily total solar radiation $\left(\mathrm{H}_{\mathrm{t}}\right)$ variation for various tilt angles

For example, in August and September, the maximum $\mathrm{H}_{\mathrm{t}}$ was between $30^{\circ}$ and $40^{\circ}$. Similar results were reported by Jafarkazemi et al. [36] and Agarwal et al. [35] for tilted surfaces facing to the south. Figure 13, presents the average daily beam $R_{b}$ factor for each month in different tilt angles. As can be observed from Figure $13, R_{b}$ increases during the winter months while, it decreases during summer months. It seems that there is a close correlation between increasing slope and increasing values of $\mathrm{R}_{\mathrm{b}}$. The same behavior was reported by El-Sebaii et al. [14] for a tilted surface. The hourly diffuse radiation of the sun and non-sun tracking are shown in
Figure14, where no significant difference is observed during the solar noon. As can be found from these results, the values of the hourly diffuse radiation for non- sun tracking are about 3 to $7 \%$ more than that of sun tracking. It can be mentioned that the scattering scope of sunlight reduced slightly during 8 to $12 \mathrm{a} . \mathrm{m}$. and 14 to $20 \mathrm{p} . \mathrm{m}$. A similar trend was reported by Wong et al. [41] and Safaripour et al. [50].

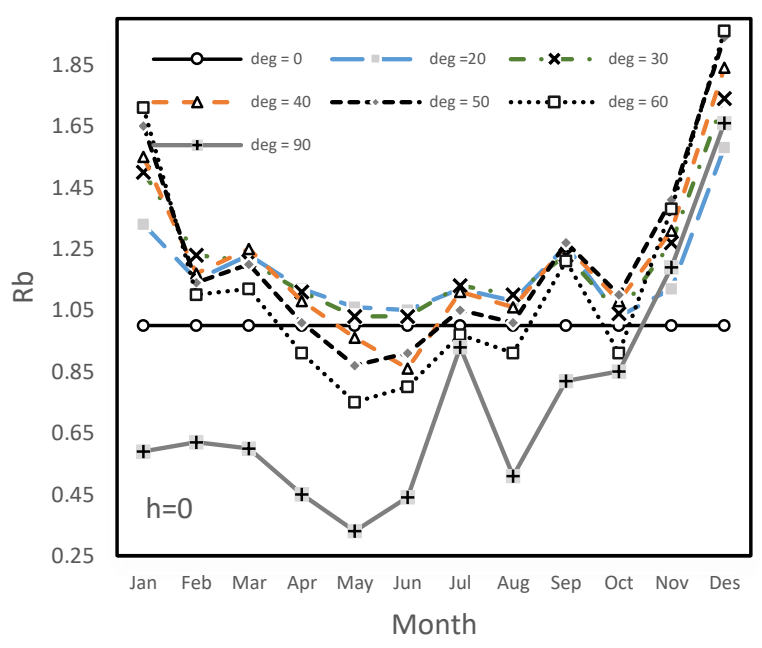

Figure 13. The average daily beam $\mathrm{R}_{\mathrm{b}}$ factor variation for each month in different tilt angles

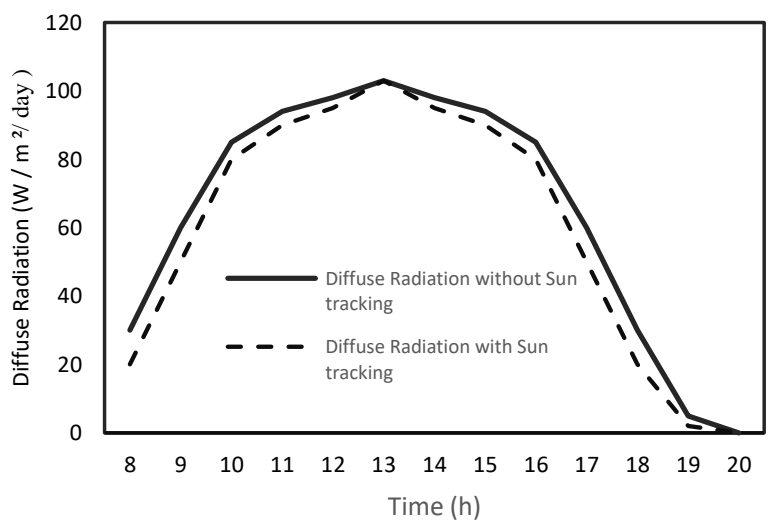

Figure 14. Comparison of diffuse solar radiation transmission for sun tracking and non-sun tracking states

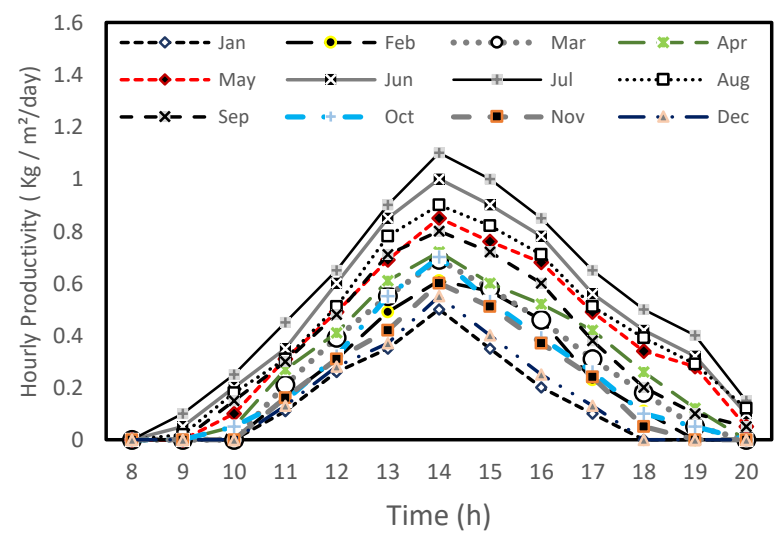

Figure 15. Variation productivity rate for sun tracking of weir type cascade solar still 


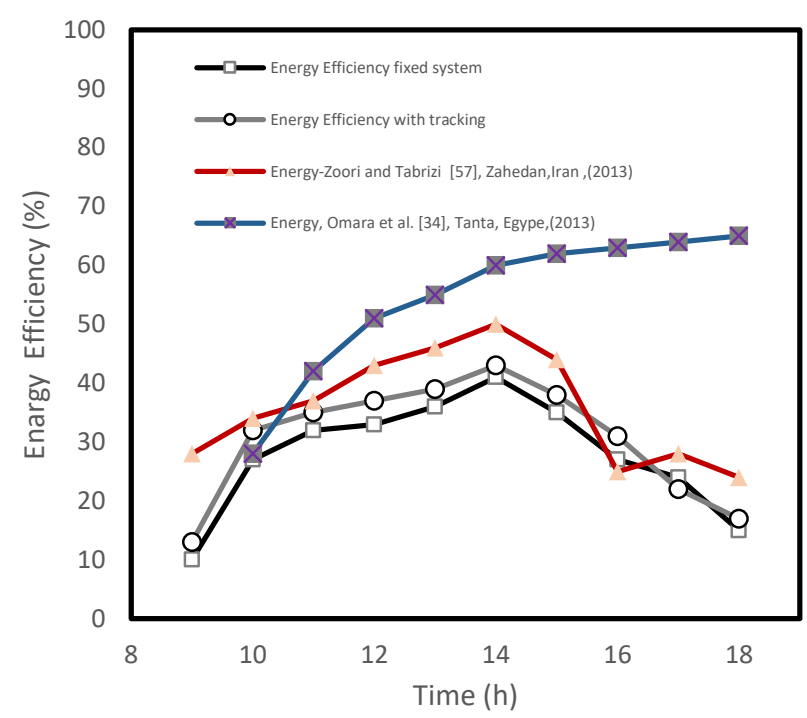

Figure 16. Hourly energy efficiencies of system

The numerically calculated data of the average monthly hourly production rate of the sun-tracking cascade solar still is reported in Figure 15. The results show that the hourly productivity increases with the rising of the solar intensity during the day. The maximum hourly productivity rate occurred between 12:00 a.m. and 2:00 p.m. The same behavior has also been obtained in non-sun tracking solar stills from the analysis of active solar distillation by Kumar and Tiwari [54] and Tripatia and Tiwari [56]. Also, similar results for cascade solar still were reported by Velmurugan et al. $[15,16]$, Tabrizi et al. [17, 18], Radhwan [51], Kabeel et al. [53], and Aybar et al. [55]. It can be estimated that the performance of the solar still with sun tracking has a 5 to $10 \%$ increase compared to the conventional solar still.

The hourly energy efficiencies of WTCSS are presented in Figure 16. It is seen that the values of energy efficiencies are about 3 to $11 \%$ and more than the fixed system. The average hourly maximum values of energy efficiency are $41 \%$ for the fixed system, $43 \%$ for tracking systems. The flow rate of water, climate conditions, solar intensity, cloudy weather, wind speed, the material of absorber plate, water depth and thermal losses influence on energy efficiency. The energy efficiencies of sysytem compare with results of stepped solar stills by Zoori et al. [57], and Omara et al. [34].

\section{CONCLUSION}

This study investigates a novel design of the hourly suntracking solar distillation system. The hourly sun tracking type cascade solar still system (WTCSS) studied in our present research includes a cascade solar still with 2-axies (an axis for tilt angles and the other one, for azimuth angles), (Lab-TAB), electromotor, solar meter, and other measuring tools. The system was fabricated and experimentally tested during two continuous days. The experimental investigation carried out just with hourly sun tracking and non-sun tracking (with fixed optimal tilt angle) to analyze the increasing the efficiency of solar radiation on the WTCSS. The hourly productivity rate was predicted for hourly sun tracking of WTCSS. The azimuth axis was adjusted in six positions in an east to west direction from the surface to the south. The adjustable tilt axis was fixed at the optimal tilt angle. The control system was controlled by
PLC and Lab-TAB bass on meteorological and geographical data and the period of time each step motor's circulation given to it.

The main conclusions extracted from this investigation are as follows:

- The maximum solar radiation calculated for sun tracking mode is about $31.5 \mathrm{MJ} / \mathrm{m}^{2} /$ day for summer.

- The received solar radiation of the tracking system on the fixed optimal tilt angle and hourly azimuth angles (for $6 \mathrm{~h}$ ) was about 10 to $30 \%$ higher than that of a horizontal surface with the non-sun - tracking system.

- The experimental results showed that the received solar intensity in hourly sun tracking mode was about 10 to $15 \%$ more than non-sun tracking mode (constant azimuth angle).

- The maximum gain for the total solar radiation $\left(\mathrm{H}_{\mathrm{t}}\right)$ in the summer months occurs between azimuths $0^{\circ}$ and $25^{\circ}$.

- The maximum gain for the total solar radiation $\left(\mathrm{H}_{\mathrm{t}}\right)$ in the winter months occurs between azimuths $45^{\circ}$ to and $65^{\circ}$.

- The maximum daily beam factor $\left(\mathrm{R}_{\mathrm{b}}\right)$ belongs to December and January months.

- Based on Dunkle model, the maximum hourly productivity of the WTCSS in sun tracking mode predicted for July and June is 1.1 and $1 \mathrm{~kg} / \mathrm{m}^{2}$, receptivity.

- The results obtained show $8.5 \%$ improvement in the average daily efficiency for the tracking solar distillation in comparison with non- sun tracking.

\section{ACKNOWLEDGMENT}

This work was supported by young Researchers and Elite Club, Islamic Azad University, Ilkhchi Branch, Ilkhchi, Iran.

\section{REFERENCES}

[1] Arnell N.W. (1999). Climate change and global water resources, Global Environmental Change, Vol. 9, pp. 31-49.

[2] Nathan M. (2009). Analysis and optimization of difusiatin-driven, multiple - effect solar still, A thesis Doctor of Philphesy, University of FLORIDA.

[3] Zell E., Gasim S., Wilcox S., Katamoura S., Stoffel T., Shiblib H., Engel-Coxa J., Al Subieb M. (2015). Assessment of solar radiation resources in Saudi Arabia, Solar Energy, Vol. 119, pp. 422-438.

[4] Carey V.P. (1992). Liquid-vapor phase-change phenomena: An introduction to the thermophysics of vaporization and condensation processes in heat transfer equipment, Hemisphere Publishing Corporation, Hebron, Kentucky.

[5] Sparrow E.M., Minkowycz W.J., Saddy M. (1967). Forced convection condensation in the presence of noncondensables and interfacial resistance, Heat and Mass Transfer, Vol. 10, pp. 1829-1845.

[6] Rose J.W. (1980). Approximate equations for forced convection condensation in the presence of a noncondensing gas on a flat plate and horizontal tube, Heat and Mass Transfer, Vol. 23, pp. 539-546.

[7] Viola A., Franzitta V., Trapanese M., Curto D. (2016). 
Nexus water \& energy: A case study of wave energy converters (WECs) to desalination applications in Sicily. Journal of Heat and Technology, Vol. 34, pp. S379S386. DOI: 10.18280/ijht.34Sp0227.

[8] Al-Shammiri M., Safar M. (1999). Multi-effect distillation plants: State of the art, Desalination, Vol. 126, pp. 45-59.

[9] Tanaka H. (2010). Monthly optimum inclination of glass cover and external reflector of a basin type solar still with internal and external reflector, Solar Energy, Vol. 84, pp. 1959-1966.

[10] Kumar S., Tiwari G.N. (1996). Estimation of convective mass transfer in solar distillation systems, Solar Energy, Vol. 57, pp. 459-464.

[11] Cucumo M., Ferraro V., Marinelli V., Cucumo S., Cucumo D. (2012). LCA analysis of a solar concentration system for the micro-chp and comparison with a PV plant., Journal of Heat and Technology, Vol. 30, No. 1. DOI: 10.18280/ijht.300110.

[12] Nasrin R., Alim M.A. (2015). Thermal performance of nanofluid filled solar flat plate collector, International Journal of Heat and Technology, Vol. 33, No. 2, DOI: 10.18280/ijht.330203.

[13] Tiwari G.N., Thomas J.M., Khan E. (1994). Optimisation of glass cover inclination for maximum yield in a solar still; 2008, Solar Energy, Vol. 14, pp. 447-455.

[14] El-Sebaii A.A., Aboul-Enein S., Ramadan M.R.I., Khallaf A.M. (2011). Thermal performance of an active single basin solar still (ASBS) coupled to shallow solar pond (SSP), Desalination, Vol. 280, pp. 183-190.

[15] Velmurugan V., Mandlin J., Stalin B., Zrithar K. (2009). Augmentation of saline streams in solar stills integrating with a mini solar pond, Desalination, Vol. 249, pp. 143-149.

[16] Velmurugan V., Pandiarajan S., Guruparan P., Subramanian H., Prabaharan D., Srithar K. (2009). Integrated performance of stepped and single basin solar stills with mini solar pond, Desalination, Vol. 249, pp. 902-909.

[17] Tabrizi F.F., Mohammad D., Hamid M. (2010). Experimental investigation of a weir-type cascade solar still with built-in latent heat thermal energy storage system, Desalination, Vol. 260, pp. 248-53.

[18] Tabrizi F.F., Dashtban M., Hamid M., Kiyanoosh R. (2010). Effect of water flow rate on internal heat and mass transfer and daily prod activity of a weir-type cascade solar still, Desalination, Vol. 260, pp. 239-47.

[19] Norozi M, Ranjbaran A., Norouzi S. (2016). Analysis and evaluation of thermodynamic parameters and heat transfer in a liner parabolic collector for design a solar desalination with sea water, conference, 2016, Azad Islamic university, Bonab branch, Iran. https://www.civilica.com/Paper-NAAME01NAAME01 020.html.

[20] Abdallah S., Nijmeh S. (2004). Two axes sun tracking system with PLC control, Energy Conversion and Management, Vol. 45, pp. 1931-1939.

[21] Mohammed S., Souda A., Abdallahb E., Akayleha A., Abdallahc S., Hrayshata E.S. (2010). A parabolic solar cooker with automatic two axes sun tracking system, Applied Energy, Vol. 87, pp. 463-470.

[22] Peragóna F.C., Peláezb P.J.C., Díaza F.A., Garcíaa R.L., Palomara J.M. (2011). An approach to evaluate the energy advantage of two axes solar tracking systems in Spain, Applied Energy, Vol. 88, pp. 5131-5142.

[23] Solomona A.A., Faimanb D., Meronc G. (2010). The effects on grid matching and ramping requirements, of single and distributed PV systems employing various fixed and sun-tracking technologies, Energy Policy, Vol. 38, pp. 5469-5481.

[24] Chong K.K., Wong C.W. (2009). General formula for on-axis sun-tracking system and its application in improving tracking accuracy of solar collector, Solar Energy, Vol. 83, pp. 298-305.

[25] Guo M., Wang Z., Liang W., Zhang X., Zang C., Lu Z., Wei X. (2010). Tracking formulas and strategies for a receiver oriented dual-axis tracking toroidal heliostat, Solar Energy, Vol. 84, pp. 939-947.

[26] Seme S., Stumberger G. (2011). A novel prediction algorithm for solar angles using solar radiation and differential evolution for dual-axis sun tracking purposes, Solar Energy, Vol. 85, pp. 2757-2770.

[27] Seme S., Stumberger B., Hadziselimovic M. (2016). A novel prediction algorithm for solar angles using second derivative of the energy for photovoltaic sun tracking purposes, Solar Energy, Vol. 137, pp. 201-211.

[28] Huang F., Li L., Huang W. (2014). Optical performance of an azimuth tracking linear Fresnel solar concentrator, Solar Energy, Vol. 108, pp. 1-12.

[29] Farooqui S.Z. (2015). Angular optimization of dual booster mirror solar cookers - tracking free experiments with three different aspect ratios, Solar Energy, Vol. 114, pp. 337-348.

[30] Farooqui S.Z. (2015). An improved power free tracking system for box type solar cookers, Solar Energy, Vol. 120, pp. 100-103.

[31] Bakos George C. (2006). Design and construction of a two-axis Sun tracking system for parabolic trough collector (PTC) efficiency improvement, Renewable Energy, Vol. 31, pp. 2411-2421.

[32] Kalogirou Soteris A. (1996). Design and construction of a one axis sun tracking system, Solar Energy, Vol. 57, pp. 465-469.

[33] Reisi A.R., Moradi M.H., Jamasb S. (2013). Classification and comparison of maximum power point tracking techniques for photovoltaic system: A review, Renewable and Sustainable Energy Reviews, Vol. 19, pp. 433-443.

[34] Omara Z.M., Kabeel A.E., Younes M.M. (2013). Enhancing the stepped solar still performance using internal reflectors, Journal of Desalination, Vol. 314, pp. 67-72.

[35] Agarwal A., Kumar Vashishtha V., Mishra S.N. (2012). Solar tilt measurement of array for building application and error analysis, International Journal of Renewable Energy Research, Vol. 2, No. 4.

[36] Jafarkazemi F. (2012). Optimum tilt angle and orientation of solar surfaces in Abu Dhabi, UAE, The International Conference on Renewable Energy: Generation and Applications,.4-7 March, Al Ain UAE.

[37] Duffie J.A., Beckman W.A. (2006). Solar Engineering of Thermal Processes, $3^{\text {rd }}$, John Wiley \& Sons, New Jersey

[38] Khalifa A.J.N., Al-Mutawalli S.S. (1998). Effect of twoaxis sun tracking on the performance of compound parabolic concentrators, Energy Convers Manage, Vol. 39, pp. 1073-9. 
[39] Sayigh A.A.M. (1997). Solar Energy Engineering, Academic Press, INC. London.

[40] Kalogirou, Soteris. (2009). Solar energy engineering: processes and systems. INC Elservier, USA,

[41] Wong L.T., Chow W.K. (2001). Solar radiation model, Applied Eng., Vol. 69, pp. 191-224.

[42] Elango C., Gunasekaran N., Sampathkumar K. (2015). Thermal models of solar still-A comprehensive review, Renewable and Sustainable Energy Reviews, Vol. 47, pp. 856-911.

[43] Tiwari G.N., Dimri V., Chel A. (2009). Parametric study of an active and passive solar distillation system: Energy and exergy analysis, Journal of Desalination, Vol. 242, pp. 1-18.

[44] Zurigat Y.H., Abu-Arabi M.K. (2004). Modelling and performance analysis of a regenerative solar desalination unit, Applied Thermal Engineering, Vol. 24, pp. 1061-1072.

[45] Stanciu C., Stanciu D. (2014). Optimum tilt angle for flat plate collectors all over the world - a declination dependence formula and comparisons of three solar radiation models, Energy Conversion and Management, Vol. 81, pp. 133-143.

[46] Oladiran M.T. (1995). Mean global radiation captured by inclined collectors at various surface azimuth angles in Nigeria, Applied Energy, Vol. 52, pp. 317-30.

[47] Ai B., Shen H., Ban Q., Ji B., Liao X. (2003). Calculation of the hourly and daily radiation incident on three step tracking planes, Energy Convers Manage, Vol. 44, pp. 1999-2011.

[48] Mousazadeh H., Keyhani A., Javadi A., Mobli H., Abrinia K., Sharifi A. (2009). A review of principle and sun-tracking methods for maximizing solar systems output, Renewable and Sustainable Energy Reviews, Vol. 13, pp. 1800-1818.

[49] Sefa I., Demirtas M., Colak I. (2009). Application of one-axis sun tracking system, Energy Convers Manage, Vol. 50, pp. 2709-2718.

[50] Safaripour M.H., Mehrabian M.A. (2011). Predication the direct, diffuse, and global radiation on a horizontal surface and comparing with real data, Heat Mass Transfer, Vol. 47, pp. 1537-1551.

[51] Radhawan A.M. (2004). Transient performance of a stepped solar still with built-in latent heat thermal energy storage, Desalination, Vol. 17, pp. 161-76.

[52] Behar O., Khellaf A., Mohammedi K. (2015). A novel parabolic trough solar collector model - validationwith experimental data and comparison to engineering equation, Energy Convers. Manag, Vol. 106, pp. 268281.

[53] Kabeel A.E., Khalil A., Omara Z.M., Younes M. (2012). Theoretical and experimental parametric study of modified stepped solar still, Desalination, Vol. 289, pp. 12-20.

[54] Kumar S., Tiwari G.N. (2010). Design, fabrication and performance of a hybrid photovoltaic thermal (PV/T) active solar still, Energy Convers. Manag, Vol. 51, pp. 1219-1229.

[55] Aybar H.S. (2006). Mathematical modeling of an inclined solar water distillation system, Desalination, Vol. 190, pp. 63-70.

[56] Tripatia T., Tiwari G.N. (2006). Thermal modeling of passive and active solar stills for different depths of water by using the concept of solar fraction, Solar Energy, Vol. 80, pp. 956-967.

[57] Zoori H.A., Tabrizi F.F., Sarhaddi F., Heshmatnezhad F. (2013). Comparison between energy and exergy efficiencies in a weir type cascade solar still, Journal of Desalination, Vol. 325, pp. 113-121.

\section{NOMENCLATURE}

\begin{tabular}{|c|c|}
\hline$A_{g}$ & surface area of glass $\left(\mathrm{m}^{2}\right)$ \\
\hline h & latent heat, hour angel \\
\hline $\bar{H}$ & global solar radiation \\
\hline $\bar{H}_{d}$ & diffuse radiation incident on horizontal surface \\
\hline $\bar{H}_{T}^{u}$ & total radiation incident on horizontal surface \\
\hline i & inlet \\
\hline$I_{c}$ & clear sky radiation $\mathrm{J} / \mathrm{m}^{2}$ \\
\hline$I_{c b}$ & horizontal beam radiation in clear sky \\
\hline$I_{c d}$ & clear sky diffuse radiation $\mathrm{J} / \mathrm{m}^{2}$ \\
\hline $\bar{I}_{d}$ & hourly diffuse radiation \\
\hline$L_{l o c}$ & longitude of the location \\
\hline$L_{s t}$ & standard meridian for local time zone \\
\hline$M_{g}$ & mass of glass effect $\left(\mathrm{kg} / \mathrm{m}^{2}\right)$ \\
\hline $\mathrm{O}$ & outlet \\
\hline$R_{b}$ & beam reflected radiation \\
\hline$R_{r}$ & ground reflected radiation \\
\hline$S_{H}$ & sun horizontal axis \\
\hline$S_{R}$ & sun reference axis \\
\hline$S_{V}$ & sun vertical axis \\
\hline$T_{s}$ & time from sunrise to sunset \\
\hline
\end{tabular}

\section{Greek symbols}

$\alpha_{\mathrm{s}} \quad$ altitude angle

$\beta \quad$ tilt angle (deg), rotational angel

$\beta_{\text {opt }} \quad$ optimal tilt angle (deg)

$\delta \quad$ declination angle, angle

$\zeta \quad$ tilt angel

$\gamma \quad$ azimuth angel

$\rho \quad$ ground reflectance

$\rho_{g} \quad$ ground reflectance factor

$\varphi \quad$ latitude of location (deg)

$\emptyset \quad$ latitude, tilt angle

$\omega_{s} \quad$ sunrise hour angle (deg)

$\omega_{S S} \quad$ sunset hour angle (deg)

\section{Appendices}

$$
\begin{aligned}
& h_{e, w-g}=\left(16.273 \times 10^{-3}\right) h_{c, w-g}\left(p_{w}-p_{g}\right) /\left(T_{w}-T_{g}\right) \\
& h_{c, w-g}=0.884\left\{\left(T_{w}-T_{g}\right)+\frac{\left[P_{w}-P_{g}\right]\left[T_{w}+273.15\right]}{\left[268.9 \times 10^{3}-P_{w}\right]}\right\}^{1 / 3} \\
& T_{s k y}=T_{a}-6 \\
& P_{i}=\exp \left[25.317-\frac{5144}{T_{i}+273}\right]
\end{aligned}
$$

